\title{
Analysis of Preoperative and Postoperative Pulmonary Hypertension Following Mitral Valve Replacement for Rheumatic Mitral Valvular Heart Disease - An Institutional study from a Tertiary Care Hospital
}

\author{
ARUNKUMAR ARASAPPA ${ }^{1}$, JAVID RAJA ${ }^{2}$, ASHIDA thulaseedharan sarojadevi ${ }^{1}$, and \\ RIAZ BAZARDEEN ${ }^{1}$ \\ ${ }^{1}$ Sri Manakula Vinayagar Medical College and Hospital \\ ${ }^{2}$ Post Graduate Institute of Medical Education and Research
}

November 12, 2020

\begin{abstract}
Background: Pulmonary Hypertension in mitral valvular heart disease leads to various adverse outcome following surgical treatment of this condition. In majority of the patients this Pulmonary Hypertension is reversible following surgery. The objective of this study is to assess the outcome of changes in Severe Pulmonary Hypertension after Mitral Valve Replacement during the follow up with postop Echocardiogram. Patients and methods: In all our 265 patients who underwent Mitral Valve Replacement Surgery (MVR) for Mitral valvular heart disease with pulmonary hypertension, females 111/195(56.9\%) outnumbered the males in this study. 195 among 265 cases had severe PHT. MVR was done with cardiopulmonary bypass using St Jude's medical valve. Results: Despite the high operative mortality in most series of MVR in patients with severe PHT, a striking improvement in survival was noted in the study with 5.3\% mortality rate.A sudden drop of PHT is not observed in our study. The fall was found to be gradual and significant over follow up and the maximum reduction was at 1-3 months post operatively. Conclusion: It is concluded that MVR reduces PHT in a gradual way and the mortality rate is also minimum in severe PHT patients. MVR thereby is an effective invasive procedure for the management of patients with severe mitral valve disease and PHT. Keywords: Severe Pulmonary Hypertension, mitral valvular disease, mitral valve replacement, Pulmonary artery pressure, Rheumatic Heart Disease
\end{abstract}

Type of article: ORIGINAL ARTICLE

Title of the article: Analysis of Preoperative and Postoperative Pulmonary Hypertension Following Mitral Valve Replacement for Rheumatic Mitral Valvular Heart Disease -An Institutional study from a Tertiary Care Hospital

Place of study: Sri Manakula Vinayakar medical college and hospital,

Pondicherry, India

CONTRIBUTORS:

Arun Kumar Arasappa* MCh.,

Javid Raja\# MCh.,

Ashida MD.,

Riaz bazardeen MCh., 
Department(s) and institution(s)

Associate Professor, Department of Cardiothoracic and vascular surgery, Sri Manakula Vinayakar Medical College and Hospital, Pondicherry, India

\# Assistant Professor, Department of Cardiothoracic and vascular surgery, Sri

Manakula Vinayakar Medical College and Hospital, Pondicherry, India

Sri Manakula Vinayakar Medical College and Hospital, Pondicherry, India

\$ Assistant Professor, Department of Cardiathoracic and vascular surgery,

Sri Manakula Vinayakar Medical College and Hospital, Pondicherry, India

CORRESPONDING AUTHOR:

Dr. ARUNKUMAR ARASAPPA

Associate professor,

Department of CTVS,

Sri Manakula Vinayagar medical college and hospital,

Pondicherry, India

Email:ddkmmc@rediffmail.com

Mobile: 9677048021

Email address of authors:

Arun Kumar Arasappa: ddkmmc@rediffmail.com : drarunkumararasappa414@gmail.com

Javid Raja: javidraj86@gmail.com

Ashida Thulaseedharan sarojadevi: drashidats@gmail.com

Riaz Bazardeen : shahul9505@yahoo.com

Presentation at a meeting: NIL

Conflicting Interest (If present, give more details): None

Informed consent: Obtained from the patients relatives

Ethical approval: Institutional ethical approval obtained

Analysis of Preoperative and Postoperative Pulmonary Hypertension Following Mitral Valve Replacement for Rheumatic Mitral Valvular Heart Disease - An Institutional study from a Tertiary Care Hospital

\section{Abstract:}

Background: Pulmonary Hypertension in mitral valvular heart disease leads to various adverse outcome following surgical treatment of this condition. In majority of the patients this Pulmonary Hypertension is reversible following surgery. The objective of this study is to assess the outcome of changes in Severe Pulmonary Hypertension after Mitral Valve Replacement during the follow up with postop ECHO.

Patients and methods: In all our 265 patients who underwent Mitral Valve Replacement Surgery (MVR) for Mitral valvular heart disease with pulmonary hypertension, females 111/195(56.9\%) outnumbered the males in this study. 195 among 265 cases had severe PHT. MVR was done with cardiopulmonary bypass using St Jude's medical valve. 
Results : Despite the high operative mortality in most series of MVR in patients with severe PHT, a striking improvement in survival was noted in the study with $5.3 \%$ mortality rate.A sudden drop of PHT is not observed in our study. The fall was found to be gradual and significant over follow up and the maximum reduction was at 1-3 months post operatively.

Conclusion : It is concluded that MVR reduces PHT in a gradual way and the mortality rate is also minimum in severe PHT patients. MVR thereby is an effective invasive procedure for the management of patients with severe mitral valve disease and PHT.

Keywords: Severe Pulmonary Hypertension, mitral valvular disease, mitral valve replacement, Pulmonary artery pressure, Rheumatic Heart Disease

\section{INTRODUCTION :}

Pulmonary Hypertension (PHT) is an increase in blood pressure in the Pulmonary artery, Pulmonary vein, or pulmonary capillaries, together known as the Lung Vasculature, leading to shortness of breath, dizziness, fainting, and others Symptoms, all of which are exacerbated by exertion. Pulmonary Hypertension can be a severe disease with a markedly decreased exercise tolerance and heart failure[1].Patients with Rheumatic Heart Disease develop Pulmonary Hypertension due to various reasons and prime cause among them will be the retrograde transmission of Left atrial hypertension which gets transmitted to the Pulmonary arteries. Pulmonary venous pressure also is transmitted to Pulmonary arteries. Pulmonary Arteriolar constriction, morphological changes in Pulmonary Vasculature and Interstitial Oedema can also lead to the development of Pulmonary Hypertension [1].

PHT was initially classified by World Health Organisation (WHO) as, Group I - Pulmonary Arterial hypertension (PAH), WHO Group II - Pulmonary Hypertension associated with left heart disease, WHO Group III - Pulmonary Hypertension associated with lung diseases and/or Hypoxemia and WHO Group IV - Pulmonary Hypertension due to chronic thrombotic and/or embolic disease by the Venice 2003 revised classification system [2].

Heath Edwards grading system classified PH into six grades based on severity and pathophysiology of the disease. Usually Pulmonary Hypertension grade 3 and below are reversible and can be taken up for surgery with better results. Pulmonary Hypertension grade 4 and above has significant contribution for postoperative morbidity and mortality [3].

Catheterization studies are not done routinely as echocardiogram has emerged as an effective tool to identify Pulmonary Hypertension and classify accordingly.

Pulmonary Hypertension in mitral valvular heart disease leads to various adverse outcomes following surgical treatment of this condition. Pulmonary Hypertension is said to complicate about $70 \%$ of the patients affected by this disease. Mitral valvular heart disease includes Mitral stenosis (MS) which refers to narrowing of the mitral valve orifice and Mitral valvular Regurgitation (MR) . It is usually caused by rheumatic heart disease [4].

Pathophysiology of Pulmonary Hypertension in Mitral Valvular heart disease in both Rheumatic Mitral Stenosis and Regurgitation can be described as follows,

Elevated LA pressureElevated Pulmonary venous pressureTransmitted pulmonary venous hypertension to arteriesVasoconstriction of Pulmonary arteriolesPulmonary Artery HypertensionRight ventricular dilatationTricuspid RegurgitationRight Atrial enlargementCongestive cardiac failure. Pulmonary Hypertension greatly influences the natural course of the disease process, treatment response and also the post intervention prognosis $[1,4 \& 7]$.

Features indicating severity of disease in mitral valvular lesions complicated by pulmonary hypertension includes, Severe Subvalvular Pathology, Small Mitral Valve Area, Higher Transvalvular gradient, Higher Pulmonary valve resistance, Higher NYHA symptoms, Thickened non pliable valves, Higher Wilkins score and Higher incidence of Atrial Fibrillation[1,4]. 
Treatment options can be medical, interventional or surgical. Rate control drugs like Betablocker and Calcium channel blockers help in reducing the transmitral gradient and hence the PHT. Digoxin is usually started for the failing heart and RV dysfunction which has to pump blood against severe PHT [6].

In interventional method for isolated MS and PHT, Balloon Mitral Valvotomy (BMV) is done in various centres.Balloon Mitral Valvotomy can be attempted only if the valves are pliable and the Wilkins score is favorable[6].There are many concerns before proceeding to BMV like the less tolerance to the stress of the procedure, difficulty in negotiating the septum in large right sided chambers, Tight Mitral Stenosis and fear of tearing the mitral valve and creating Mitral Regurgitation[6].

Various options are open for surgical management of Mitral Valvular heart disease like Mitral valve replacement (MVR), Closed Mitral Commisurotomy and Open Mitral Valvotomy. Mitral Valve Replacement may be done with either mechanical prosthetic valve or Bioprosthetic Valve, Autologous transfer of Pulmonary valve (ROSS II PROCEDURE) has also been done for this condition[6] .Pulmonary Hypertension regresses after the transmitral gradient gets reduced following surgery[8].

The objective of this study is to analyze the reduction in Pulmonary Hypertension following mitral valve replacement during patient follow up post surgically.An attempt of a prospective study to analyze the facts is made and the results are tabulated and compared to the national and international views on the same parameter of this common disease. The results obtained from the data collection were tabulated and analyzed.

\section{PATIENTS AND METHODS:}

A total of 265 patients were taken in this prospective study that came to the hospital with NYHA Class II-IV symptoms and with Mitral valvular heart lesions comprising of Mitral stenosis and Mitral Regurgitation with Pulmonary Hypertension from period of July 2016 -July 2017.

A detailed clinical examination and investigations were done on these patients and were categorized according to the study. All patients were prepared and consented before surgery as per the protocol and institutional ethical clearance was obtained before surgery. All of them underwent Mitral valve replacement using St Jude's mechanical valve using cardiopulmonary bypass support (Figure 1).

A detailed clinical findings and preoperative values of the patients were recorded over a structured proforma for all the patients.All the patients are classified according to their age, sex, diagnosis, preoperative and post-operative echo findings and results after surgery. The results thus obtained are tabulated, analysed and conclusions drawn thereafter.

Operative procedure:

In all the 265 patients who underwent MVR, 195 of them had severe PHT . All of them had the classical left atrial approach through Sondergaard's groove incision except 11 cases which was approached through the septum after opening the right atrium. All cases were operated through the standard median sternotomy and were done using cardiopulmonary bypass utilizing cardioplegic arrest to open the chamber (s) (Figure 2). In about 195 out of 265 patients (73.58\%), MVR was done with either partial or complete chordal preservation. All the patients had St Jude's mechanical prosthetic valve (Figure 2).

Except for the 14 deaths which occurred due to low cardiac output failures, all other cases were weaned of the ventilator by day 1 and from the inotropic supports by day 2 or day 3.Those patients who had severe Pulmonary Hypertension who underwent MVR were followed up using echo at day 0, 3 months and 6 months.

\section{Results:}

Quantitative variables were expressed as mean, standard deviation. Qualitative variables were expressed as proportions.

Data analysis was done using SPSS version 16.0 
According to the age group distribution of the disease (severe PHT), we can see from the fig $\mathbf{3}$, that the age group affected is mostly from $20 \mathrm{yrs}$ to $50 \mathrm{yrs}(90.1 \%)$. This is a productive age group and needs to be addressed carefully

While considering the sex of the population affected its seen that females are slightly more affected $(54.7 \%)$ compared to males $(45.3 \%)$ as evident from the fig 4 .

On comparing the tables 1 and 2, we could decipher that most of the patients in the preoperative period were in class III NYHA (67.5\%) and were symptomatically improved to NYHA class II (68.7\%). On performing the chi square test it was statistically found to be significant $\mathrm{p}<0.001$

On statistically analyzing the results for the regression in Pulmonary Hypertension following Mitral valve Replacement in our study, we could definitely appreciate that the regression starts from the first month of post surgical period and continues till 3 months post surgical period ( $\mathrm{p} 0.026$; p0.095) Table 3 which is quite significant statistically.It's quite interesting to note that the regression is not appreciable after 3 months as is evident from the fig. 3

The Kaplan Meir curve depicts the drastic regression at 1 month of surgery and gradual regression thereafter in the following months.

As far as the age groups are compared it's not statistically seen that significant regression occurs following Mitral Valvular Replacement due to severe pulmonary Hypertension. In other words Age doesn't influence much in the regression of PHT after Mitral valve replacement in patients with severe PHT preoperatively[Table 5 ].

\section{DISCUSSION :}

Normal Pulmonary arterial pressure in a person living at sea level has a mean value of $12-16 \mathrm{~mm} \mathrm{Hg} \mathrm{(1600-}$ $2100 \mathrm{~Pa}$ ). Pulmonary Hypertension is present when mean Pulmonary artery pressure exceeds $25 \mathrm{~mm} \mathrm{Hg}$ $(3300 \mathrm{~Pa})$ at rest or $30 \mathrm{~mm} \mathrm{Hg}(4000 \mathrm{~Pa})$ with exercise [9].

PHT can be idiopathic or familial with various underlying causes and classifications. PHT classifications were modified regularly for better understanding of the disease the latest modification was done in Nice, France 2013. [Table 1] The reduction of PHT following MVR is not well understood and relies on various factors $[10,11]$. This is a follow up study providing information on the agenda.

In all our 265 patients who underwent MVR, 195 had severe Pulmonary Hypertension females $111 / 195(56.9 \%)$ outnumbered the males in this diagnosis. The immediate reduction of Pulmonary Hypertension happened in only approximately $21 \%$ of the patients and the remaining had persistent PHT which showed a fall progressively following a 1-3 months period suggesting the various factors which might be responsible for the Pulmonary Hypertension.

Yang and colleagues found the long term survival was inversely related to the degree of PHT and had an early (30 day) mortality of $9 \%$ in patients with severe PHT, However in our study it was found to be only $5.3 \%$. But it needs further follow up of these patients in the long run. [12].

Cesjnvar et al has reported higher early mortality among his series of 382 patients who underwent MVR for Mitral Valvular disease with Pulmonary Hypertension. But the late mortality was no different among patients with or without Pulmonary Hypertension [13].In our study the mortality was 5.3\%, which was less compared to the previous studies. The difference might be because of the earlier decision to operate upon this severe group before irreversible factors sets in and also due to the better intraoperative and postoperative care using latest agents so far approved for this purpose.

Most studies have demonstrated an immediate reduction in PAP and PVR, signifying a sudden drop in left atrial pressure and reversal of the severe spastic pulmonary vasoconstriction that accompanies left atrial hypertension in some patients [10\& 14]. Others have shown slow regression of elevated PAP and PVR several months postoperatively [14]. These reports point toward the involvement of multiple factors in 
the development of PAH in mitral valve disease [14]. In our study the mean PAP and PVR did not fall significantly immediately following MVR. The mean fall in PAP was about $46.1 \mathrm{mmHg}$ in $1^{\text {st }}$ month and 38.9 $\mathrm{mmHg}$ in the $3^{\text {rd }}$ month follow up after surgery, which was against the previous views.

Reduction of PHT is not random after MVR and is found to be reducing gradually at 1 and 3 months in our study. This analysis showed that the reduction in PHT had a gradual course. This gives us a clue that the reduction in Pulmonary Hypertension is a gradual one and needed change in organic level as well as in the dynamic level which takes some time to achieve [15-20].

However, the long-term follow up of these patients are needed to conclude firmly regarding reduction of PHT postoperatively.

\section{CONCLUSION:}

We conclude that MVR is safe and effective even in the presence of severe PHT as long as the pulmonary arterial pressures are below systemic pressures. With suprasystemic PHT, MVR carries a high risk of mortality, and the patient continues to have persistent PHT in the postoperative period. Significant reduction in PHT following MVR takes place only gradually and in this study about 1 to 3 months period showed a decline in PHT as compared to the previous belief of immediate reduction in PHT in majority of the patients. This explains the multifactorial causes of PHT in patients with Rheumatic mitral valvular heart disease and severe PHT.

\section{LIMITATIONS :}

Lack of follow-up of Pulmonary vascular dynamics by catheterization constitutes a limitation of this study and was related primarily to economic factors. A postoperative lung biopsy might have added to the information, but this was not undertaken as most of the patients refused consent for it.

\section{References:}

1. Magne J, Pibarot P, Sengupta PP, Donal E, Rosenhek R, Lancellotti P. Pulmonary hypertension in valvular disease: a comprehensive review on pathophysiology to therapy from the HAVEC Group. JACC Cardiovasc Imaging (2015) 8(1):83-99. 10.1016/j.jcmg.2014.12.003 [PubMed] [CrossRef] [Google Scholar

2 .Rich S, Rubin LJ, Abenhail L, et al. Executive Summary From the World Symposium on Primary Pulmonary Hypertension (Evian, France; September 6-10, 1998). Geneva, Switzerland: World Health Organization; 1998:1-27.Google Scholar

3. Heath D, Edwards JE. The pathology of hypertensive pulmonary vascular disease; a description of six grades of structural changes in the pulmonary arteries with special reference to congenital cardiac septal defect. Circulation . 1958;18(4, pt 1):533-547

4. Weitsman T, Weisz G, Farkash R, Klutstein M, Butnaru A, Rosenmann D, et al. Pulmonary hypertension with left heart disease: prevalence, temporal shifts in etiologies and outcome. Am J Med (2017) 130(11):12729. 10.1016/j.amjmed.2017.05.003 [PubMed] [CrossRef] [Google Scholar]

5. Simonneau G, Gatzoulis MA, Adatia I, et al. Updated clinical classification of pulmonary hypertension published correction appears in J Am Coll Cardiol . 2014; 63(7):746]. J Am Coll Cardiol. 2013;62(25)(suppl):D34-D41.

6. N. Galie, M. Humbert, J.L. Vachiery, et al. 2015 ESC/ERS Guidelines for the diagnosis and treatment of pulmonary hypertension: The Joint Task Force for the Diagnosis and Treatment of Pulmonary Hypertension of the European Society of Cardiology (ESC) and the European Respiratory Society (ERS): Endorsed by: Association for European Paediatric and Congenital Cardiology (AEPC). International Society for Heart and Lung Transplantation (ISHLT) Eur Heart J, 37 (2016), pp. 67-119

[CrossRef][View Record in Scopus][Google Scholar] 
7.Simonneau G, Montani D, Celermajer DS, et al. Hemodynamic definitions and updated clinical classification of pulmonary hypertension. Euro Respir J 2019; 53.

8. Guidelines on the management of valvular heart disease: The Task Force on the Management of Valvular Heart Disease of the European Society of Cardiology. Eur

Heart J. 28: 2007; 230-268.

9. Kaul TK,Bain WH, Jones Jr, Lorimer AR, Thomsen RM, Turner MA et al :

Mitral Valve Replacement in the presence of severe Pulmonary Hypertension.

THORAX 1976; 31: 332

10. Reeve R, Selzer, A., and Popper R. w., Leeds R F., and Gerbode .F. 1966:

Reversibility of Pulmonary Hypertension following Cardiac Surgery. Circulation, 33,

Supplement 1, 107.

11. Vachiéry JL, Tedford RJ, Rosenkranz S, et al. Pulmonary hypertension due to left heart disease. Eur Respir J 2019;53:1801897.

12. Yang B, Debenedictus C, Watt T, Farley S, Salita A, Hornsby W, et al. The impact of concomitant pulmonary hypertension on early and late outcomes following surgery for mitral stenosis. J Thorac Cardiovasc Surg (2016) 152(2):394-400. 10.1016/j.jtcvs.2016.02.038 [PubMed] [CrossRef] [Google Scholar]

13. Cesnjevar ra, Feyrer R, Walther F,Mahmoud FO,Lindemann Y,von der Emde

J.High risk Mitral valve replacement in severe Pulmonary Hypertension.-30 years

Experience. European J cardiothoracic surg1998; 13:344-51

14. Walls MC, Cimino N, Bolling SF, Bach DS.Persistent Pulmonary Hypertension after

Mitral valve surgery. Does surgical procedure affects the outcome? J Heart Valve

Disease. 2008; 17:1-9.

15. Vachiéry JL, Adir Y, Barberà JA, Champion H, Coghlan JG, Cottin V, De Marco T, Galiè N, Ghio S, Gibbs JS, et al.. Pulmonary hypertension due to left heart diseases.J Am Coll Cardiol . 2013; 62(25 suppl):D100-D108. doi: 10.1016/j.jacc.2013.10.033 [Crossref][Medline][Google Scholar]

16. Mentias A, Patel K, Patel H, Gillinov AM, Sabik JF, Mihaljevic T, et al. Effect of pulmonary vascular pressures on long-term outcome in patients with primary mitral regurgitation. J Am Coll Cardiol (2016) 67(25):2952-61. 10.1016/j.jacc.2016.03.589 [PubMed] [CrossRef] [Google Scholar]

17. Pourafkari L, Ghaffari S, Ahmadi M, Tajlil A, Aslanabadi N, Nader ND. Pulmonary hypertension in rheumatic mitral stenosis revisited. Herz (2017) 42(8):746-51. 10.1007/s00059-016-4509-2 [PubMed] [CrossRef] [Google Scholar]

18. . Braunwald E, Braunwald .s, Ross J Jr, Morrow AG. Effects of Mitral Valve

Replacement on the pulmonary vascular Dynamics of patients with Pulmonary

Hypertension. N.ENGL J MED 1965; 273; 509.

19. M. Guazzi, B.A. Borlaug. Pulmonary hypertension due to left heart disease. Circulation, 126 (2012), pp. $975-990$

20. Dalen JF, Matloff JM , Evans GL, Hoppin FG Jr, Bhardwaj P, Harken DE et al

: Early Reduction of Pulmonary vascular Resistance after Mitral Valve Replacement. 
N. ENGL.J.Med 1967; 277; 387.

Figure 1: Rheumatic Mitral Valve Exposure on Cardiopulmonary Bypass

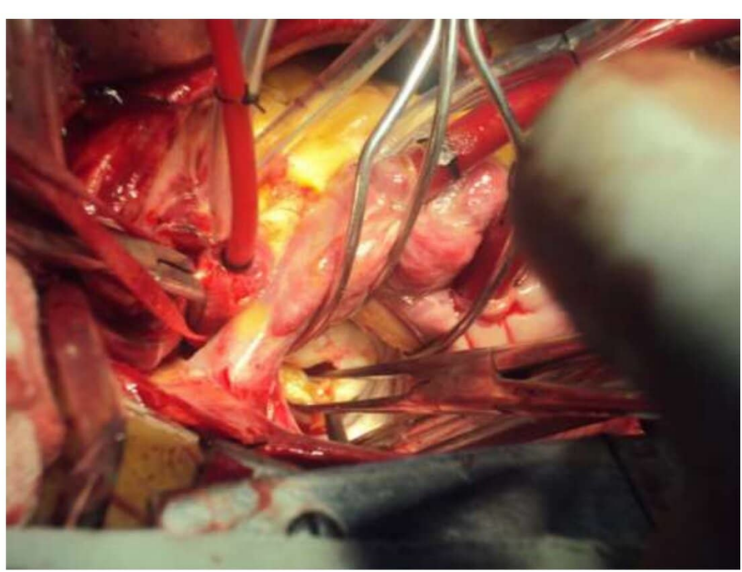


Figure 2: Insertion of ST JUDE'S Mechanical Prosthetic Valve in Mitral Position

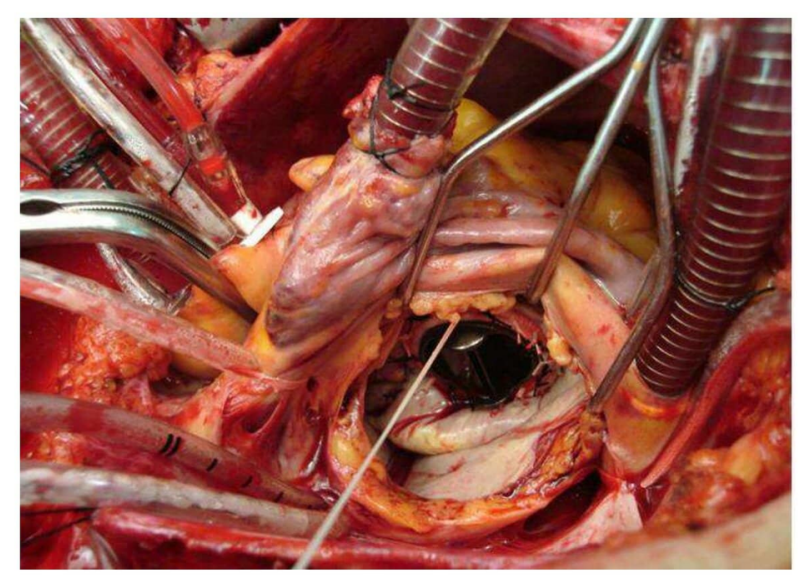




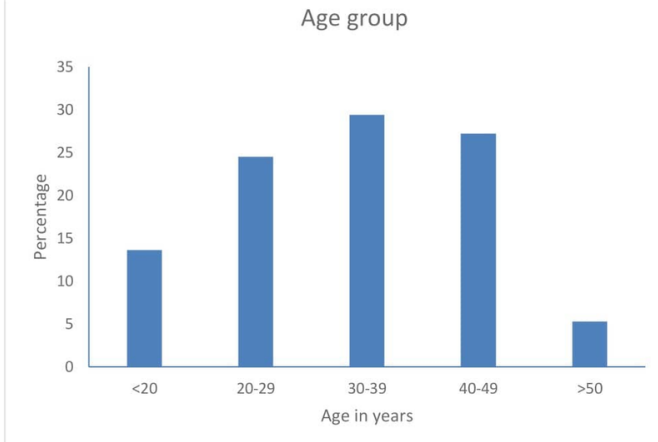

FIG 3: Age group affected with severe pulmonary hypertension 


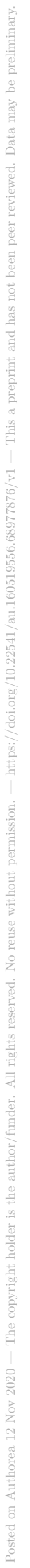

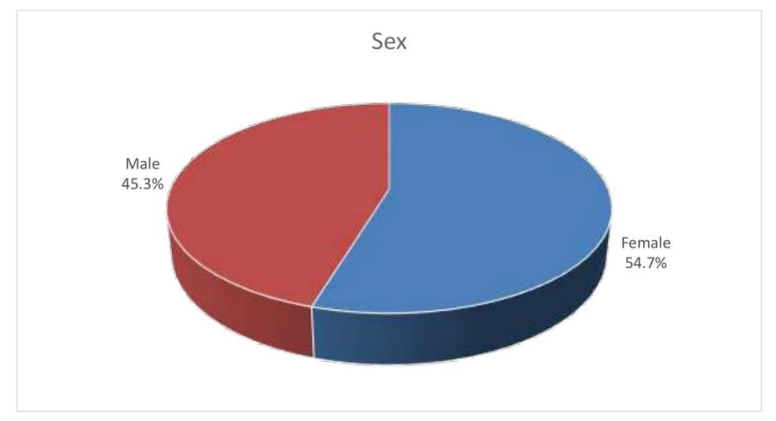

FIG 4: sex distribution of patients affected with severe pulmonary Hypertension due to mitral valvular heart disease

11 


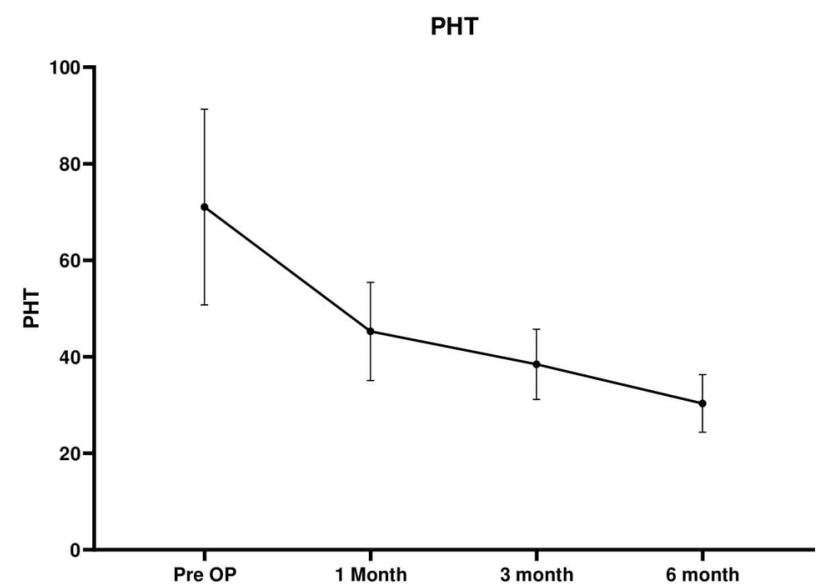

Fig 5: Kaplan Meir curve depicting the regression of pulmonary Hypertension post mitral valvular heart Replacement

\section{Hosted file}

TAB 1.pdf available at https://authorea.com/users/375336/articles/492596-analysisof-preoperative-and-postoperative-pulmonary-hypertension-following-mitral-valvereplacement-for-rheumatic-mitral-valvular-heart-disease-an-institutional-study-froma-tertiary-care-hospital

\section{Hosted file}

TABLE 2.pdf available at https://authorea.com/users/375336/articles/492596-analysisof-preoperative-and-postoperative-pulmonary-hypertension-following-mitral-valvereplacement-for-rheumatic-mitral-valvular-heart-disease-an-institutional-study-froma-tertiary-care-hospital

\section{Hosted file}

TABLE 3.pdf available at https://authorea.com/users/375336/articles/492596-analysis- 
of-preoperative-and-postoperative-pulmonary-hypertension-following-mitral-valvereplacement-for-rheumatic-mitral-valvular-heart-disease-an-institutional-study-froma-tertiary-care-hospital

\section{Hosted file}

TABLE 4.pdf available at https://authorea.com/users/375336/articles/492596-analysisof-preoperative-and-postoperative-pulmonary-hypertension-following-mitral-valvereplacement-for-rheumatic-mitral-valvular-heart-disease-an-institutional-study-froma-tertiary-care-hospital

\section{Hosted file}

TABLE 5.pdf available at https://authorea.com/users/375336/articles/492596-analysisof-preoperative-and-postoperative-pulmonary-hypertension-following-mitral-valvereplacement-for-rheumatic-mitral-valvular-heart-disease-an-institutional-study-froma-tertiary-care-hospital 